\title{
Limitations of diagnostic value of the sweat test
}

\author{
V. SCHWARZ, NAOMI I. M. SIMPSON, AND A. S. AHUJA \\ From the Departments of Child Health and Medical Biochemistry, University of Manchester, and the Royal \\ Manchester Children's Hospital
}

SUMMARY The sweat test, even if carried out by an experienced technician, sometimes lacks reproducibility owing presumably to physiological variations (patient's diet, temperature, and other factors at present unrecognized). Some patients are particularly prone to exhibit this variability and in them a single sweat test is almost valueless. The aldosterone status is believed to be responsible for a reciprocal relationship between sweat sodium and potassium concentrations: tests done on 8 patients show that a high sweat potassium is associated with a correspondingly lower sodium-a circumstance which must be borne in mind when interpreting a patient's sweat sodium.

Of 30 patients presenting with a variety of symptoms compatible with a diagnosis of cystic fibrosis and with sweat sodium ranging from 50 to $75 \mathrm{mEq} / \mathrm{l}(50-75 \mathrm{mmol} / \mathrm{l})$, only 4 have proved to have cystic fibrosis after several years of observation; 13 have later been diagnosed as having asthma. The problem of the 'grey area' of uncertainty is aggravated by the heterozygous state which is also associated with a sweat sodium in this range. Repeated sweat tests are indicated if the sweat sodium lies within the 'grey area', and the diagnostic importance accorded the test should diminish as the sodium value approaches this area. The diagnosis of cystic fibrosis must remain in doubt unless there is strong supportive clinical evidence.

Since the discovery of the sweat abnormality in cystic fibrosis (CF) by Darling et al. (1953), the sweat test has rightly established itself as the single most reliable laboratory test for this disease. With the assumption that earlier diagnosis and treatment improve the prognosis has come an even greater reliance on the diagnostic value of the test. Thus, the very concept of screening implies an ability to diagnose $\mathrm{CF}$, albeit tentatively, by this criterion alone. Several warnings have been sounded against the practice of basing the diagnosis on this laboratory test in the absence of adequate clinical evidence (Gibson, 1972; di Sant'Agnese, 1972; Committee, Testing for CF, 1976), warnings which are lent greater urgency by the notoriously poor performance of the test in many laboratories. But even in experienced hands the test is not wholly reliable, with several physiological aspects of sweat elaboration remaining unexplored or unexplained.

It is with the children and their parents in mind, whose lives may be drastically affected by a wrong diagnosis based on inadequate evidence, that we present the following laboratory and clinical data on some 30 patients whose sweat sodium concentrations

Received 28 March 1977 might well have led to false conclusions by the criteria laid down in the literature. The patients belong to a group of about 2000 children on whom we have carried out more than 3000 sweat tests over the last 15 years.

\section{Methods}

Our sweat test is based on that of Gibson and Cooke (1959) with some modifications as described previously (Schwarz et al., 1968), the main difference being that we collect sweat for 4-6 consecutive periods of 5 minutes on separate papers which are analysed individually, thus yielding several values of sodium concentration ([Na]) for each test. To enable comparisons with the standard method to be made, individual values have been pooled and the true mean for a 20-minute collection has been calculated.

Some patients with a presumed temporary hyperaldosteronism were treated as follows: spironolactone (Aldactone, Searle), either in alcoholic solution or incorporated in a water-soluble base, was applied 2-3 times to an area of the forearm which was covered by dry gauze. After 24 hours the area was stimulated with pilocarpine in the usual manner to induce sweat secretion. 


\section{Results}

It is well known that neither the secretion rate nor the [Na] of the sweat remains constant throughout a 20 - or 30-minute collection period. During the first few minutes the secretory rate often rises and then falls off gradually over the next 25 minutes, whereas [Na] usually drops steadily (Sutcliffe et al., 1968; Schwarz, 1968). The serial collection therefore offers the dual advantage of multiple samples for analysis and information on the changing secretion rate and electrolyte levels, whereas a single 30-minute sample yields mean values for both.

The results obtained in our sweat test are illustrated by two representative examples in Table 1 , which shows clearly the variation of the secretion rate and of sweat [Na] during the collection. The mean [Na] calculated for the 20-minute collection does not, however, differ substantially from the 30-minute mean. The error introduced by comparing our 20 -minute mean [Na] values with the usual 30-minute values reported in the literature is considerably smaller than the reproducibility of the sweat test and can therefore be ignored.

Table 2 gives details of the patients' symptoms when first seen, [Na] in the sweat obtained at various times, and the present symptoms and diagnosis at patients' ages varying from 2-19 years. It includes an assessment of four sibs of established $\mathrm{CF}$ patients. Most of the sweat [Na] values in the table are at some time in the region $50-75 \mathrm{mEq} / 1$ (50-75 mmol/1), considered to be suspect or abnormal (Committee, Testing for CF, 1976). In several cases a lack of reproducibility is evident, which further aggravates the diagnostic problem posed by these patients.

Occasionally patients are seen in whom, presumably, temporary hypersecretion of aldosterone has depressed the sweat [Na] while raising that of potassium concentration $([\mathrm{K}]$.) Application of spironolactone to an area of skin before performing a sweat test at that site results in a partial reversal of the aldosterone effect, a process which can be seen to take place spontaneously if a second sweat test is done some time later. Our findings in $\mathbf{8}$ such cases are recorded in Table 3. The inverse relationship between [Na] and [K], indicative of an exchange mechanism, is apparent. It further complicates the interpretation of a single test.

\section{Discussion}

The sweat test is now firmly established as a valuable aid in the diagnosis of $\mathrm{CF}$, but its limitations are insufficiently appreciated. The importance of an adequate secretion rate is well known, yet it is widely disregarded by those using laboratory methods in which the rate cannot be assessed. In so far as such methods are used for screening only and are followed by the standard test, no great harm is done, although cases of CF may be missed if the sweat electrolyte concentration is low due to an inadequate secretion rate.

Yet, determination of the weight of sweat collected is itself a poor guide to the parameter of real significance-the load on the gland, since it takes no account of the number or the size of the glands involved. Our inability to control the load on the glands may well contribute to the variability of their performance. A certain lack of reproducibility of the sweat test has been referred to (McKendrick, 1962) and is evident from our results presented in Table 2 (Cases 11-26). It renders repeat tests essential in all but the most clear-cut cases with electrolyte levels lying well outside the 'grey area' of uncertainty.

Especially remarkable is Case 26 whose sweat [Na] values span an extraordinarily wide range, the fluctuations having been observed in two laboratories using different methods. Although this girl has no steatorrhoea and no evidence of immunodeficiency, she presented in 1976 with signs and symptoms typical of $\mathrm{CF}$, including recurring bronchopneumonia and pneumothorax, a chest $x$-ray consistent with CF,

Table 1 Serial sweat collection in 2 children (not with CF)

\begin{tabular}{|c|c|c|c|c|c|c|}
\hline \multirow{2}{*}{$\begin{array}{l}\text { Sweat collected } \\
\text { at (min) }\end{array}$} & \multicolumn{3}{|l|}{ Case 16} & \multicolumn{3}{|l|}{ Case 9} \\
\hline & $\begin{array}{l}\text { Secretion } \\
\text { rate } \\
\left(\mathrm{mg} / 5 \mathrm{~min} \text { per } 9 \mathrm{~cm}^{2}\right)\end{array}$ & \multicolumn{2}{|c|}{$[N a](m E q / l)$} & $\begin{array}{l}\text { Secretion } \\
\text { rate } \\
\left(\mathrm{mg} / 5 \min \text { per } 9 \mathrm{~cm}^{2}\right)\end{array}$ & \multicolumn{2}{|c|}{$[N a](m E q / l)$} \\
\hline $\begin{array}{c}0-5 \\
5-10 \\
10-15 \\
15-20 \\
20-25 \\
25-30\end{array}$ & $\begin{array}{l}27 \cdot 6 \\
37 \cdot 8 \\
44 \cdot 4 \\
41 \cdot 4 \\
37 \cdot 1 \\
32 \cdot 1\end{array}$ & $\begin{array}{l}63 \cdot 7 \\
62 \cdot 9 \\
61 \cdot 8 \\
56 \cdot 2 \\
52 \cdot 7 \\
42 \cdot 8\end{array}$ & $\begin{array}{l}61 \cdot 2(20 \mathrm{~min}) \\
56 \cdot 7(30 \mathrm{~min})\end{array}$ & $\begin{array}{l}62 \cdot 7 \\
69 \cdot 0 \\
60 \cdot 3 \\
53 \cdot 7 \\
45 \cdot 3 \\
34 \cdot 5\end{array}$ & $\begin{array}{l}78 \cdot 2 \\
72 \cdot 2 \\
70 \cdot 1 \\
64 \cdot 0 \\
60 \cdot 5 \\
51 \cdot 9\end{array}$ & $\begin{array}{l}71 \cdot 1(20 \mathrm{~min}) \\
66 \cdot 2(30 \mathrm{~min})\end{array}$ \\
\hline
\end{tabular}

Conversion: Traditional units to $S I-\mathrm{Na}: 10 \mathrm{mEq} / 1=10 \mathrm{mmol} / 1$. 
Table 2 Early symptoms, sweat sodium, and present diagnosis in 30 children not considered to have CF

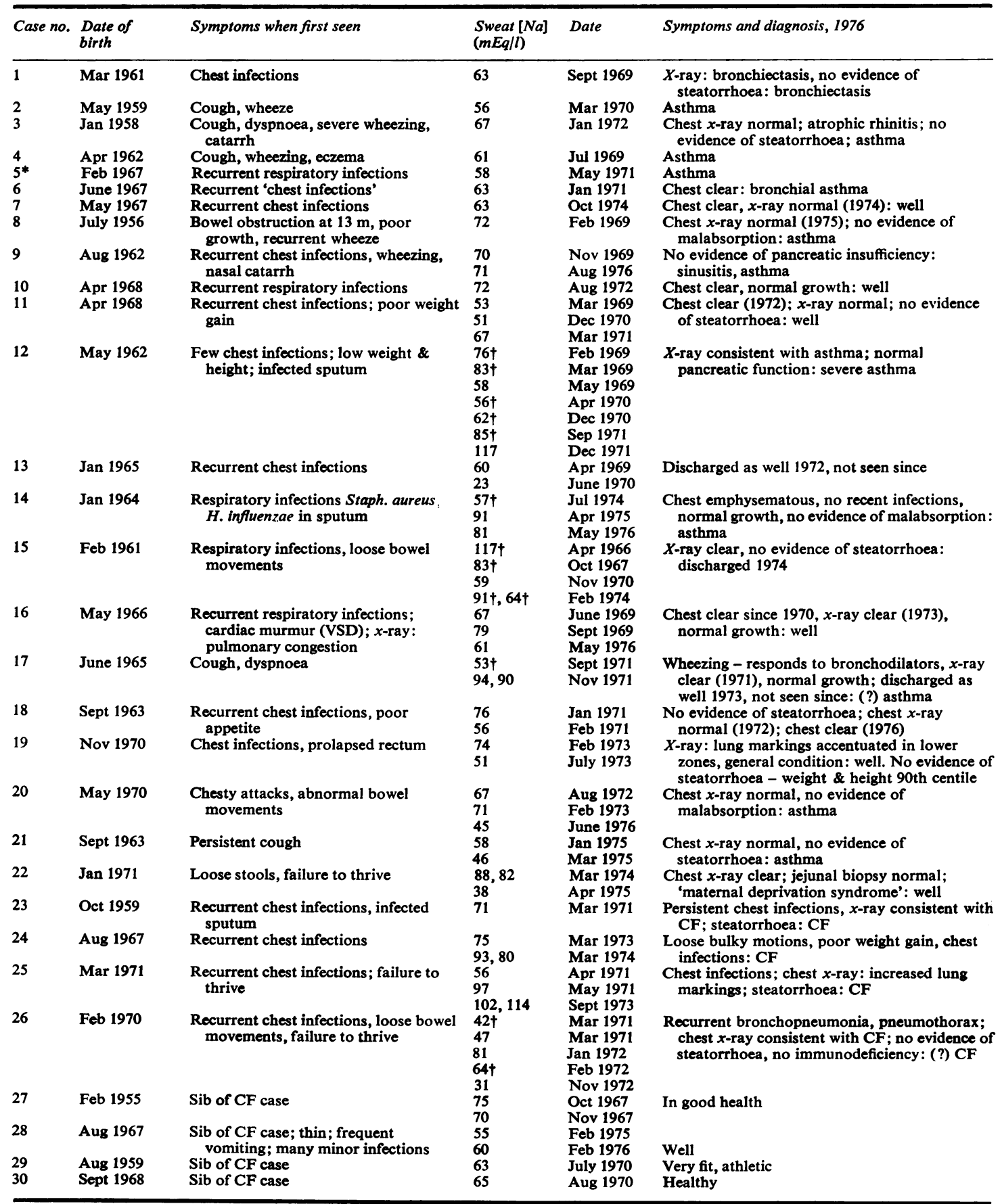

*Another 4 cases similar to Case 5, with sweat [Na] 60, and definitely not CF, have been omitted from this table. †Standard test performed at Booth Hall or Royal Manchester Children's Hospitals, Manchester. 
Table 3 Presumed temporary hyperaldosteronism in 8 cases: effect on sweat test

\begin{tabular}{|c|c|c|c|}
\hline Case no. & Date of test & $\begin{array}{l}{[N a](\mathrm{mEq} / \mathrm{l})} \\
(20 \text { min means) }\end{array}$ & $\begin{array}{l}{[K](\mathrm{mEq} / \mathrm{l})} \\
(20 \text { min means })\end{array}$ \\
\hline 31 & $\begin{array}{l}12 \text { Feb } 1970 \\
5 \text { Nov } 1970\end{array}$ & $\begin{array}{r}91 \\
119\end{array}$ & $\begin{array}{l}30 \\
15\end{array}$ \\
\hline 32 & $\begin{array}{l}9 \text { June } 1970 \\
9 \text { June } 1970^{*}\end{array}$ & $\begin{array}{l}89 \\
95\end{array}$ & $\begin{array}{l}32 \\
26\end{array}$ \\
\hline 33 & $\begin{array}{l}15 \text { June } 1968 \\
8 \text { Oct } 1970\end{array}$ & $\begin{array}{r}72 \\
127\end{array}$ & $\begin{array}{l}44 \\
25\end{array}$ \\
\hline 34 & $\begin{array}{l}21 \text { Mar } 1967 \\
14 \text { Jan } 1976\end{array}$ & $\begin{array}{r}59 \\
117\end{array}$ & $\begin{array}{l}40 \\
29\end{array}$ \\
\hline 35 & $\begin{array}{l}18 \text { Feb } 1969 \\
29 \text { Dec } 1969 \\
29 \text { Dec } 1969 *\end{array}$ & $\begin{array}{l}72 \\
87 \\
95\end{array}$ & $\begin{array}{l}33 \\
26 \\
13\end{array}$ \\
\hline 36 & $\begin{array}{l}21 \text { Mar } 1968 \\
8 \text { Dec } 1969\end{array}$ & $\begin{array}{r}60 \\
119\end{array}$ & $\begin{array}{l}56 \\
22\end{array}$ \\
\hline 37 & $\begin{array}{l}19 \text { June } 1968 \\
12 \text { Nov } 1968\end{array}$ & $\begin{array}{l}74 \\
88\end{array}$ & $\begin{array}{l}23 \\
15\end{array}$ \\
\hline 38 & $\begin{array}{l}19 \text { May } 1971 \\
16 \text { July } 1971\end{array}$ & $\begin{array}{l}79 \\
93\end{array}$ & $\begin{array}{l}41 \\
24\end{array}$ \\
\hline
\end{tabular}

*After 24 hours' application of spironolactone.

and sputum infected with Staphylococcus aureus, Haemophilus influenzae, Klebsiella, and Pseudomonas.

Cases 23, 24, and 25 are the only others whose clinical presentation in 1976 was compatible with a diagnosis of CF. Of the 30 patients with 'borderline' sweat $[\mathrm{Na}]$ in Table 2,11 had no signs or symptoms whatever at the time of writing (Cases $7,10,11$, $13,15,16,22,27-30$ ), while the remainder have a variety of conditions none of which, in the opinion of several paediatricians, is CF.

It is noteworthy that 13 of the 30 children listed have been found to have asthma. Yet the 4 known sibs quoted have no signs of allergy.

Examination of the sweat $[\mathrm{Na}]$ in Table 2 will indicate the approximate delimitation of the area of uncertainty. A precise delineation is clearly impossible and indeed undesirable. The evidence presented here should be sufficient to discourage the use of 'cut-off' values above or below which CF or normal status respectively can be inferred. In single or even in repeated tests, 'high' sweat [Na] lying above the upper limit for normal advocated in published reports (Anderson and Goodchild, 1976; Committee, Testing for CF, 1976) are clearly compatible with normal status.

It may be argued that a convincing case has not been made for the normal status of some of our patients, and it is indeed possible that one or other may develop unmistakable symptoms of CF in the future, despite the gradual, sometimes complete, disappearance over several years of observation of the signs with which he presented originally. But we think that the evidence is overwhelming that the sweat electrolyte levels are sufficiently variable, being subject to a number of known and unknown, and in any case uncontrollable, influences for the result of a sweat test to be regarded with great caution if it falls into the 'grey' area.

After years of experience administering a very large number of sweat tests we are convinced that a diagnosis of CF is never justified on the basis of the sweat test alone. This conviction is shared by others (Gibson, 1972; di Sant'Agnese, 1972; Anderson and Goodchild, 1976). Screening, if considered desirable at all, should therefore be undertaken with this in mind. Further, the test should be interpreted not in terms of some arbitrary 'cut-off' value or even of a precisely delineated 'grey area', but in the light of relevant factors like the secretory rate and the potassium concentration of the sweat, and the patient's clinical history and his age. The importance of the latter does not seem to be widely recognized, with the emphasis in published reports on puberty obscuring what may be a steady rise in sweat $[\mathrm{Na}]$ up to and beyond puberty, probably referable to a gradually increasing salt intake. The test should be repeated if the result is at variance with the clinical picture, or if it lies within the 'grey area'. Contrary to the statement (Anderson and Goodchild, 1976) that the test can be used quite satisfactorily to exclude the diagnosis in sibs, we conclude from our Cases 27-30 that a definitive placing in the absence of symptoms is often difficult and that the 'grey area' has to be extended upwards to accommodate such cases.

For the diagnosis of $\mathrm{CF}$ in cases which are clinically not clear-cut, the use of a points system has been advocated (M. D. Warwick, personal communication, 1976), in which each diagnostic sign or symptom is given some points and a minimum total of points is required for a definitive diagnosis. In such a system we suggest fewer points be awarded to a sweat [Na] of $75 \mathrm{mEq} / 1$ than to one of 120 , and fewer still to one of 65 .

We thank the following for permission to include their patients in this study: Professor A. Holzel, Professor J. Davis, Drs. J. D. Allen, W. Dickson, G. V. Feldman, R. M. Forrester, D. Hilson, C. R. Jayachandra, D. Macaulay, N. M. Mann, R. G. McGucken and W. Turner; and the Cystic Fibrosis Research Trust and the Loyal Order of Moose for generous financial support to one of us (V.S.). 


\section{References}

Anderson, C. M., and Goodchild, M. C. (1976). Cystic Fibrosis, p. 142. Blackwell, Oxford.

Committee for a Study for Evaluation of Testing for Cystic Fibrosis (1976). Journal of Pediatrics, 88, 711-750.

Darling, R. C., di Sant'Agnese, P. A., Perera, G. A., and Andersen, D. H. (1953). Electrolyte abnormalities of sweat in fibrocystic disease of the pancreas. American Journal of the Medical Sciences, 225, 67-70.

di Sant'Agnese, P. A. (1972). Comment on sweat tests. Journal of Pediatrics, 81, 196-197.

Gibson, L. E. (1972). Reliability of sweat tests in diagnosis of cystic fibrosis. Journal of Pediatrics, 81, 193-194.

Gibson, L. E., and Cooke, R. E. (1959). A test for concentration of electrolytes in sweat in cystic fibrosis of the pancreas, utilizing pilocarpine by iontophoresis. Pediatrics, 23, 545-549.
McKendrick, T. (1962). Sweat sodium levels in normal subjects, in fibrocystic patients and their relatives, and in chronic bronchitic patients. Lancet, 1, 183-186.

Schwarz, V. (1968). Cystic Fibrosis. CIBA Foundation Study Group No. 32. Ed. by R. Porter and M. O'Connor. Churchill, London.

Schwarz, V., Sutcliffe, C. H., and Style, P. P. (1968). Some hazards of the sweat test. Archives of Disease in Childhood, 43, 695-701.

Sutcliffe, C. H., Style, P. P., and Schwarz, V. (1968). Biochemical studies of sweat secretion in cystic fibrosis. Proceedings of the Royal Society of Medicine, 61, 297-300.

Correspondence to Dr. V. Schwarz, Department of Medical Biochemistry, University of Manchester Medical School, Stopford Building, Oxford Road, Manchester M13 9PT. 